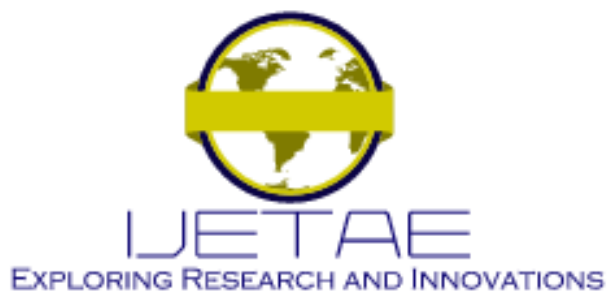

International Journal of Emerging Technology and Advanced Engineering

Website: www.ijetae.com (E-ISSN 2250-2459, Scopus Indexed, ISO 9001:2008 Certified Journal, Volume 12, Issue 02, February 2022)

Manuscript Received: 22 December 2021, Received in Revised form: 02 January 2022, Accepted: 05 February 2022

DOI: $10.46338 /$ ijetae0222_05

\title{
Hand Gesture Recognition as Signal for Help using Deep Neural Network
}

\author{
Nathasia Florentina Thejowahyono ${ }^{1}$, Michael Vincentius Setiawan ${ }^{2}$, Seto Benson Handoyo ${ }^{3}$, Abdul Haris Rangkuti ${ }^{4}$ \\ ${ }_{1,2,3,4}$ Informatics Department, School of Computer Science, Bina Nusantara University, Jakarta-11480 Indonesia.
}

\begin{abstract}
Hand gesture recognition research has increased widely and rapidly to overcome various problems in human life. When in a dangerous situation humans are required to act quickly and precisely, such as being a victim of violence, accidents, disasters, and so on. In the asking process for help, it is necessary to use an appropriate safe method, communication tools, and speed in sending messages requesting help so that something unwanted does not happen. One of the ways to overcome this problem is to use sign language such as hand gestures. So that this study designs and develops a real-time hand gesture recognition system as signal for help using Deep Neural Network. The purpose of this research is to simplify, speed up, and produce a safe way that humans can use when asking for help from others without speaking when in danger happen. Base on the experiment that real-time detection and an average accuracy of $98.79 \%$. When the system detects a hand gesture to ask for help, a request for help message will be sent to the designated emergency email. So that the benefits derived from the design and development of this system are convenience, speed, and safety in the process of asking for help when humans are in a dangerous situation.
\end{abstract}

Keywords - Hand gesture recognition, Signal for help, Deep Neural Network, Dangerous Situation, Emergency Email.

\section{INTRODUCTION}

Technology that involves interaction between humans and computers has increased widely and rapidly with various methods and techniques to overcome various problems in human life [4]. Human-computer interaction methods mainly include voice interaction and gesture interaction [2] because gestures contain a lot of information that can convey semantics, emotions and conform to human daily life habits [13]. The gesture can be in the form of a hand gesture that allows us to express our thoughts clearly in our everyday interactions [4]. Gesture recognition is a mathematical interpretation of human movement by computing devices [6]. Hand gesture recognition can help physically disabled people to communicate with others [15-16].
With the development in the fields of deep learning and computer vision, hand gesture recognition technology has developed to interpret sign gestures in an understandable way [1] and classify within a certain area of interest [17]. The success of deep learning techniques implementation in various fields such as image classification and object recognition has driven the development and application of hand recognition technology [8]. By applying the concept of artificial intelligence which has increased rapidly over time, hand gesture recognition technology allows computers to recognize human hand movements which are symbols of physical or emotional expressions [19-20]. Hand gesture recognition models use various devices to recognize hand movements [12]. Hand gestures can be used as sign language to convey information [9-11], as humans use when in danger to ask for help from others. When in a dangerous situation humans are required to act quickly and precisely [18], for example being a victim of violence, accidents, disasters, and so on. In the process of asking for help, it is necessary to use an appropriate safe method, communication tools, and speed in sending requesting help so that something unwanted happens. One of the ways to overcome this problem is use sign language such as in Figure 1.

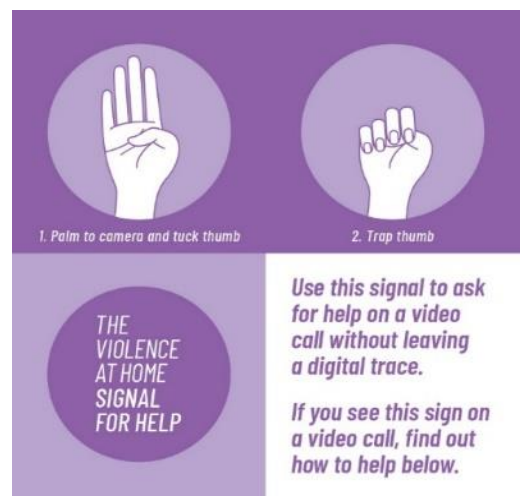

Figure 1. Signal for Help (The Canadian Women's Foundation) 


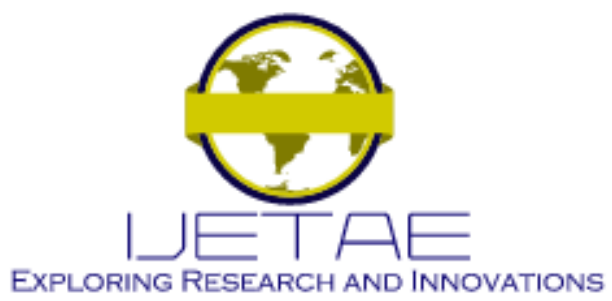

International Journal of Emerging Technology and Advanced Engineering Website: www.ijetae.com (E-ISSN 2250-2459, Scopus Indexed, ISO 9001:2008 Certified Journal, Volume 12, Issue 02, February 2022)

In 2020, the world organization called The Canadian Woman introduced hand signals or hand signals that have a function for humans to tell others that they are in a dangerous situation and need help immediately. Through this hand signal, humans can ask other people for help secretly and safely to give information that they feel they are in danger and are threatened. Signal for Help is a tool that can help humans to ask for help quickly when a dangerous situation occurs at home and cannot communicate. So that this study designs and develops an real-time hand gesture recognition system using Deep Neural Network as an signal for help when in danger and providing information on requests for help via email that can overcome the problems described previously. Deep Neural Network is part of Artificial Neural Network (ANN) which has more than one hidden layer between the input layer and the output layer. ANNs are parallel computing systems consisting large number of simple processors with many interconnections [5]. So that the concepts of machine learning and deep learning are used for development of this hand gesture recognition technology so that a system that can recognize human hand gestures can be developed. The proposed system will perform real-time detection. Help request information will be sent via the specified emergency email when the system detects a request for help signal made by the user. So with this system, humans can ask for help quickly, easily, and safely when in a dangerous situation. So with this system, humans can ask for help quickly, easily, and safely when in a dangerous situation.

\section{RELATED STUDY}

The process of developing this system and research uses several references from international journals related to research and the system being developed. These references were used to find information and analyze previous research that has similar objectives to the current research. So it can find out about the differences and value from this research compared to previous research. In the field of machine learning or deep learning, hand gesture recognition is a challenging problem to solve. Because classification methods can be divided into several methods and algorithms. In 2021, Aripita Halder and Akshit Tayade demonstrate a methodology that simplifies real-time sign language recognition using the open-source MediaPipe framework and a machine learning algorithm, namely, Support Vector Machine (SVM).
With an average accuracy of $99 \%$, the proposed model is efficient, precise, and robust to assist the communication process for deaf people. [1]. And there is research that discusses the development of real-time hand gesture recognition based on deep learning in complex environments by Weixin $\mathrm{Wu}$ el al. in 2019. The purpose of this research is to design and develop a real-time hand gesture recognition method from video streams with Deep Learning CNN algorithm in a complex environment with accuracy of $96 \%$ [2]. In addition, there is research conducted by Abdullah Muhajid et al. in 2021 which discusses hand gesture recognition for help disabilities in communicating by proposing a lightweight model based on YOLO (You Only Look Once) v3 and CNN for gesture recognition and to determine the accuracy of the algorithm that is $97.68 \%$ [3].

The reference journals above discuss the research and development of hand gesture recognition can be used as references in this research. This research designs and develops a hand gesture recognition system as a signal to ask for help which will be developed using Deep Neural Network and MediaPipe. Then after the hand signal is detected, the system performs rescue information with an email sending system using Simple Mail Transfer Protocol (SMTP) to send a message requesting help. So that the research and the developed system have differences in terms of hand movements that will be recognized, namely as a signal to ask for help and more value in terms of how the system works and functionality as signal for help. The reviews and comparisons with related studies are described in the following Table 1.

TABLE 1

REVIEW AND COMPARISON OF RELATED STUDY

\begin{tabular}{|l|l|l|l|l|}
\hline Reference & Classes & Purpose & Method & Accuracy \\
\hline $\begin{array}{l}\text { Arpita } \\
\text { Halder et } \\
\text { al. (2021) }\end{array}$ & 10 & $\begin{array}{l}\text { Numbers } \\
\text { Sign } \\
\text { Language }\end{array}$ & SVM & $99.18 \%$ \\
\hline $\begin{array}{l}\text { Weixin Wu } \\
\text { et al. } \\
(2019)\end{array}$ & 8 & $\begin{array}{l}\text { Video } \\
\text { Streams }\end{array}$ & CNN & $96 \%$ \\
\hline $\begin{array}{l}\text { Abdullah } \\
\text { Mujahid et } \\
\text { al. (2021) }\end{array}$ & 5 & $\begin{array}{l}\text { Number } \\
\text { Sign } \\
\text { Language }\end{array}$ & CNN & $97.68 \%$ \\
\hline $\begin{array}{l}\text { Nathasia, } \\
\text { Michael, } \\
\text { Seto \& } \\
\text { Abdul } \\
\text { (2021) }\end{array}$ & $\mathbf{9}$ & $\begin{array}{l}\text { Signal for } \\
\text { Help }\end{array}$ & DNN & $\mathbf{9 8 . 7 9 \%}$ \\
\hline
\end{tabular}




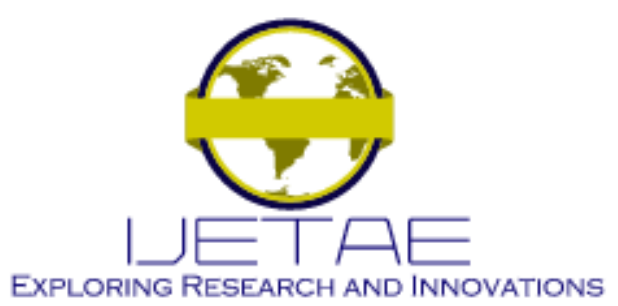

International Journal of Emerging Technology and Advanced Engineering

Website: www.ijetae.com (E-ISSN 2250-2459, Scopus Indexed, ISO 9001:2008 Certified Journal, Volume 12, Issue 02, February 2022)

\section{RESEARCH METHOD}

The system development method used in this study is the Waterfall Prototyping method which consists of 5 stages, that are communication (project initiation and requirements gathering), planning (estimation, scheduling, and tracking), modelling (analysis and design), construction (code and test), and development (delivery, feedback, and support). The research scheme in developing a hand gesture recognition as signal for help is divided into 5 main stages, starting from:

\section{A. Hand gesture determination}

To build the proposed system, the first step is to determine the hand gestures that will be recognized by the system along with the meaning of these hand gestures. After that, this study will use OpenCV and Mediapipe framework to perform hand and extract landmarks from detected hands. Key point landmarks from gestures that will be recognized will be input for conducting training data. And every gesture will be trained with Deep Neural Network with Python programming language along with library TensorFlow, Keras, NumPy, Pandas, etc. to be recognized by the system. All the hand gesture sign can be seen in Table 2.

TABLE 2

HAND GESTURES THAT THE SYSTEM WILL RECOGNIZE

\begin{tabular}{|c|c|}
\hline Label & Gesture \\
\hline Need Help & \\
\hline SFH (Signal for help) & \\
\hline Need police & \\
\hline Need Ambulance & \\
\hline
\end{tabular}

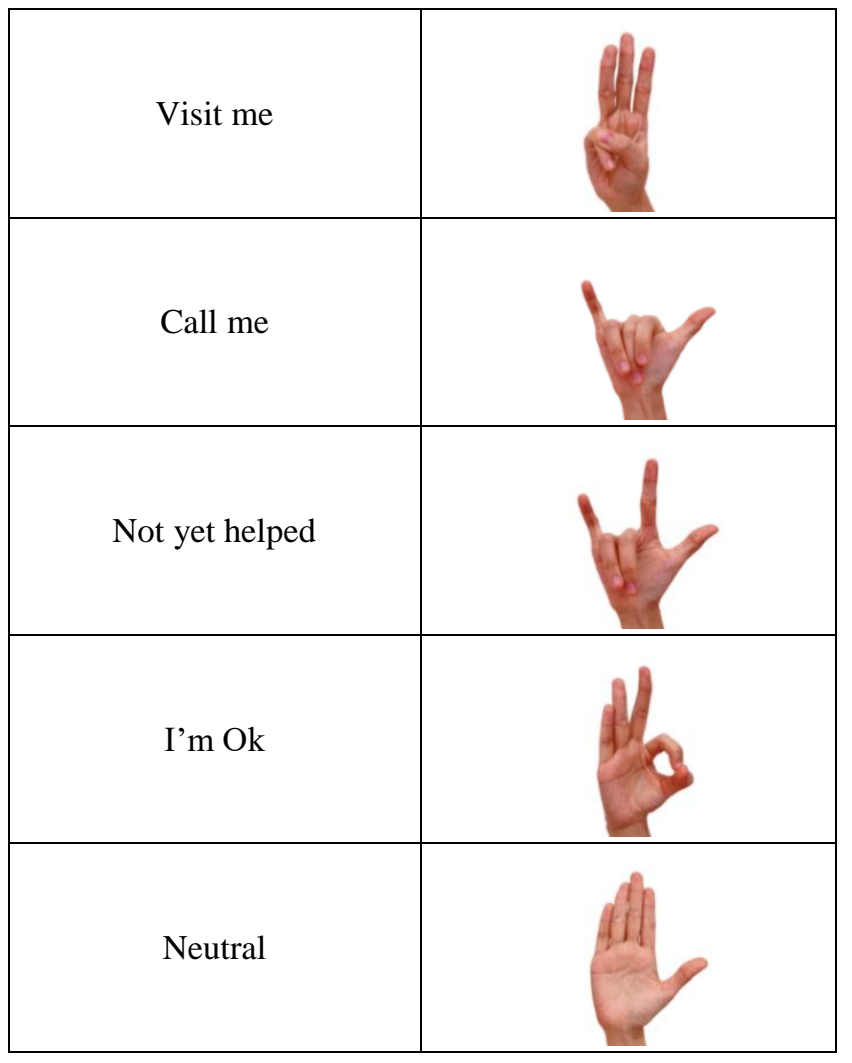

Hand gestures that will be recognized by the system are informed in Table 2. Based on this Table that the development of this system used 9 hand gestures that will be recognized by the system. Each gesture has a different label and meaning to use as a signal for help.

\section{B. Hand Tracking with Media Pipe}

The Media Pipe uses machine learning which consists of several methods that are interconnected and work together. The first model is to detect the palm of the image which is considered as input. This model will return a hand-oriented bounding box from the captured palm image. The bounding box will be used to crop the hand image and then the landmark model of the hand will be described as highfidelity 3D hand key points. The overall process of hand tracking using MediaPipe can be seen in Figure 2. 


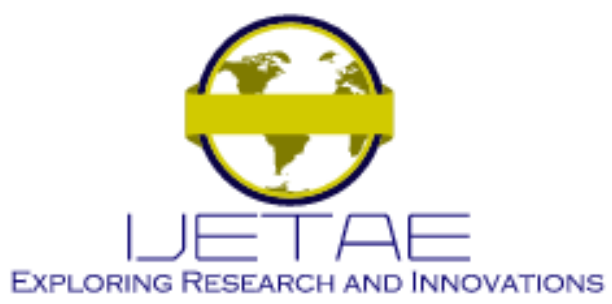

International Journal of Emerging Technology and Advanced Engineering

Website: www.ijetae.com (E-ISSN 2250-2459, Scopus Indexed, ISO 9001:2008 Certified Journal, Volume 12, Issue 02, February 2022)

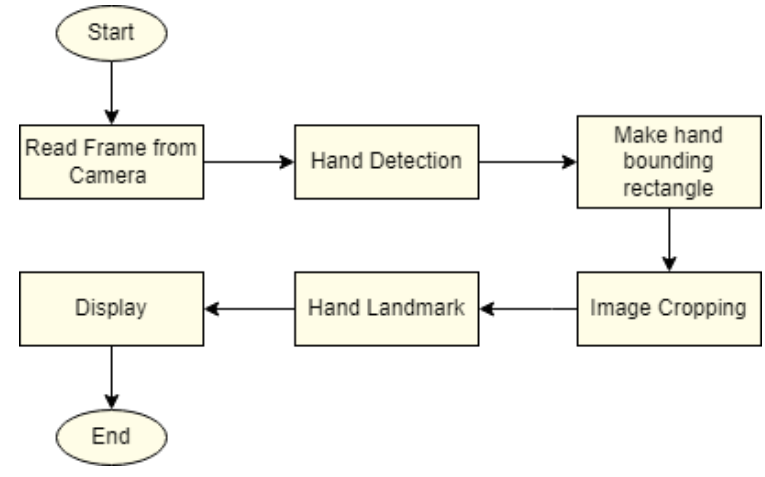

Figure 2. The process of hand tracking using MediaPipe

To detect the initial location of the palm, the MediaPipe framework provides a single-shot detector model optimized for real-time deployment. To perform the function of detecting palms, MediaPipe needs to adjust the size of the hand with a relatively large-scale range that can be captured by the frame. This is done using the concept of machine learning, first the system will be trained to detect the palm of the hand because the palm is a small object compared to the whole hand. In addition, the palm can be modelled with the help of a square box as a delimiter by ignoring the ratios of other aspects. Then for the next, the encoder-decoder extractor feature will be used to increase awareness for larger contexts and also for small objects. The last step is the framework will minimize the possibility of losing focus to support the training and hand gesture recognition process.

The second model in MediaPipe's hand tracking process is the hand landmark model. After the palm is detected in the image through the palm detection model process, the next process is to find and localize the 21 coordinates in the detected hand through a regression process which will predict the coordinates directly. The following Figure 3 is the hand landmarks that will be generated from the hand tracking process using a Mediapipe.
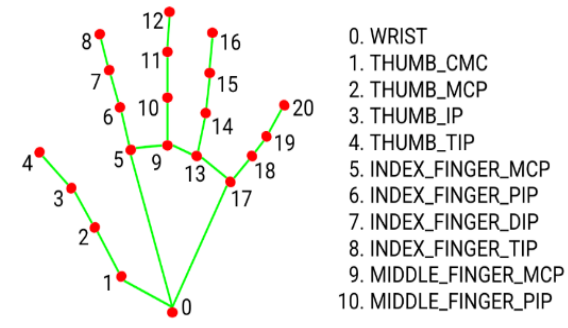

11. MIDDLE_FINGER_DIP 12. MIDDLE_FINGER_TIP

13. RING_FINGER_MCP

14. RING_FINGER_PIP

15. RING_FINGER_DIP

16. RING_FINGER_TIP

17. PINKY_MCP

18. PINKY_PIP

19. PINKY_DIP

20. PINKY_TIP

\section{Training data using Deep Neural Network}

Deep Neural Networks are made by programming PCs to act as though they were interconnected brain cells to understand the information provided. These neurons are organized in a series of layers, and are referred to as units.

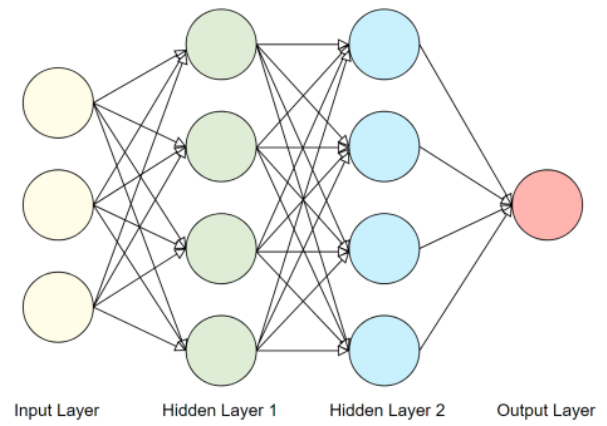

Figure 4. Architecture of Deep Neural Network algorithm

Based on Figure 4, Deep Neural Network has more than one layer between the input and output layers. This study uses 2 hidden layer. There is an input layer that is utilized to get different sorts of information received from users that will be handled and studied by network so that by studying the data the system can develop and become better. After the input section, the data will continue and pass through one or more hidden units. The task of the hidden unit is to convert the input data into data that can be used by the output unit. The following are training process with the Deep Neural Network in this study can be seen in Figure 5.

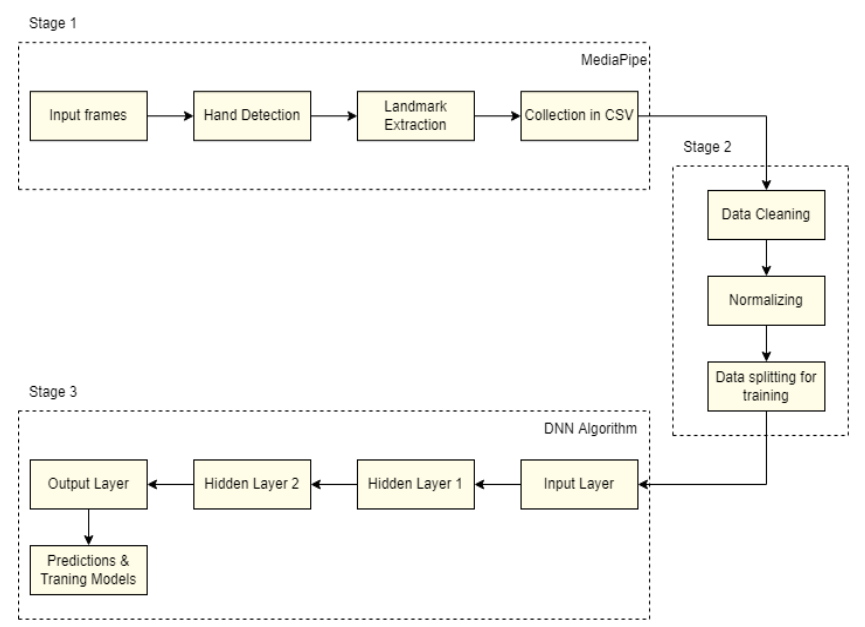

Figure 5. Architecture to training data using Deep Neural Network

Figure 3. Hand Landmarks (MediaPipe, 2020) 


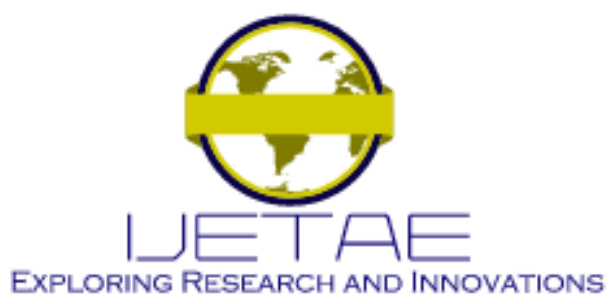

International Journal of Emerging Technology and Advanced Engineering Website: www.ijetae.com (E-ISSN 2250-2459, Scopus Indexed, ISO 9001:2008 Certified Journal, Volume 12, Issue 02, February 2022)

Figure 5 inform that the data training process with Deep Neural Network consists of 3 stages. The first stage will perform hand detection from input frame and extract landmarks from detected hands. Each gesture will be gathered around 600 landmark key points. Key point landmarks from gestures will be saved in the form of a CSV file. Then in the second stage, the data will be cleaned first to ensure there are no null entries in the datasets and followed by the process of normalizing the coordinates to fit the system. In the third stage, after preparing the data as input, the next step is to build a model using the Deep Neural Network. The hand landmarks coordinates will be used as input. The first and second hidden layers have the same properties where both are consist dense layer followed by a Rectified Linear Unit (ReLU) activation function and dropout layer which serves to remove fraction units to go to the next layer. The last layer is the output layer followed by Softmax activation function to generate predictions. Each predicted output is a label probability index of gestures.

\section{Hand Gesture Recognition}

After the training is complete, the system can recognize the specified hand gestures, so the following outlines the working process of the hand gesture recognition system as a signal to ask for help can be seen in the following Figure 6.

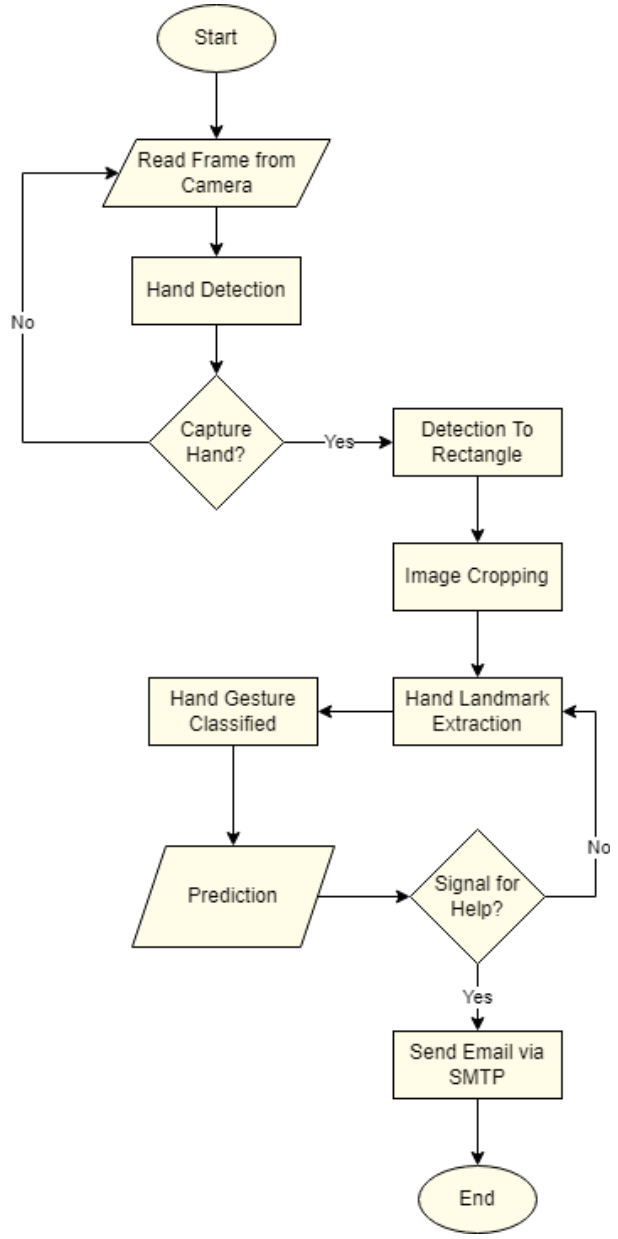

Figure 6. Flowchart of hand gesture recognition system 


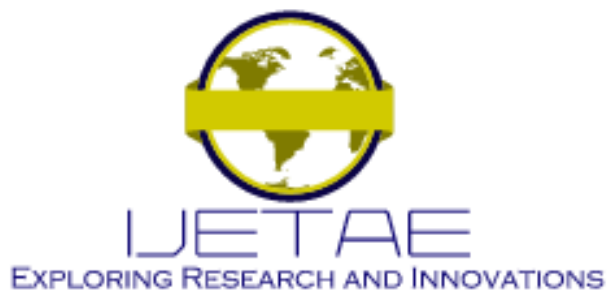

International Journal of Emerging Technology and Advanced Engineering

Website: www.ijetae.com (E-ISSN 2250-2459, Scopus Indexed, ISO 9001:2008 Certified Journal, Volume 12, Issue 02, February 2022)

In Figure 6 is the process of operation of the hand gesture recognition system as a signal for a request for help begins from the camera reading the frame image in realtime. Then, at that point, the system will detect the presence of the hand in the frame. When a hand is detected, the system calculates the bounding box for the detected hand and crops the image based on the bounding box. When a hand is detected, the system considers the hand landmark and draws the hand landmark. After the hand landmarks are extracted, the system classifies the gestures made by the user according to the previously performed training model. The system generates predictions and recognizes them from the hand gestures made. If the gesture made is included in the help request signal, the system emails a help request message containing the content of the message according to the detected gesture.

\section{E. Sending Email using SMTP}

If the specified hand gesture is detected by the system then the system will send the information via the specified emergency email with SMTP. The following Figure 7 is the process of sending email using SMTP.

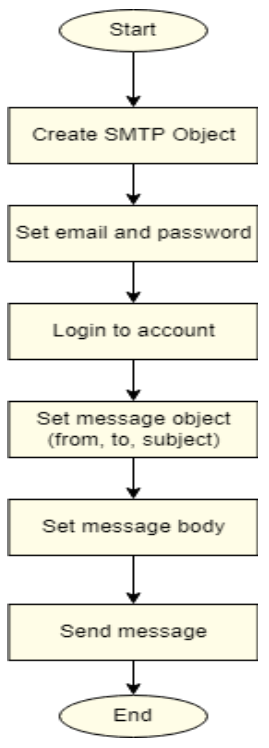

Figure 7. The process of sending an email using SMTP

In Figure 7, to process email using SMTP via Python, you must first set up an SMTP server. Python provides a smtplib module that can be pre-imported to define the SMTP object used to send email. After importing the smtplib module and setting the SMTP object, the next step is to $\log$ in to the program with an email and password.
Then specify from, to, and subject data for the message object. Next, set and specify the content of the message to be sent. The message can then be sent via SMTP. The combinations of hand gestures for sending a help request are in Table 3.

TABLE 3

HAND GESTURE TO EMAIL A REQUEST FOR HELP

\begin{tabular}{|c|c|}
\hline Hand Signal & Message \\
\hline & $\begin{array}{l}\text { My name is }\{\text { name }\}, \text { I } \\
\text { am in danger and I } \\
\text { need help immediately. } \\
\text { I'm at }\{\text { location }\}\end{array}$ \\
\hline & $\begin{array}{l}\text { My name is \{name }\} \text {, } \\
\text { please call police for } \\
\text { me. I need the police } \\
\text { for come to }\{\text { location }\end{array}$ \\
\hline & $\begin{array}{l}\text { My name is \{name } \text {, } \\
\text { please call ambulance } \\
\text { for me. I need the } \\
\text { ambulance for come to } \\
\text { \{location\} }\end{array}$ \\
\hline & $\begin{array}{l}\text { My name is }\{\text { name }\}, I \\
\text { need you for visit me at } \\
\text { \{location }\end{array}$ \\
\hline & $\begin{array}{l}\text { My name is }\{\text { name }\}, I \\
\text { need you to call me at } \\
\text { \{phone number }\}\end{array}$ \\
\hline & $\begin{array}{l}\text { My name is }\{\text { name }\}, \text { I } \\
\text { am in danger and not } \\
\text { yet helped, please help } \\
\text { me. I'm at \{location }\}\end{array}$ \\
\hline & $\begin{array}{l}\text { My name is \{name }\} \text {, } \\
\text { I've been fine, thank } \\
\text { you very much for the } \\
\text { help. }\end{array}$ \\
\hline
\end{tabular}




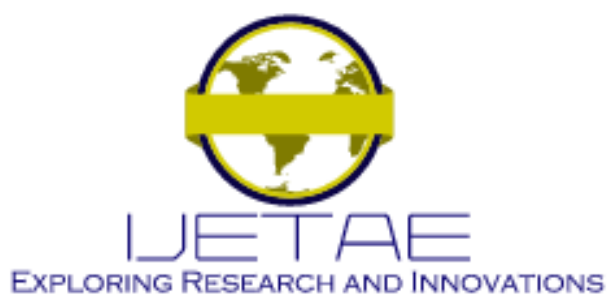

International Journal of Emerging Technology and Advanced Engineering

Website: www.ijetae.com (E-ISSN 2250-2459, Scopus Indexed, ISO 9001:2008 Certified Journal, Volume 12, Issue 02, February 2022)

\section{RESULT AND DISCUSSION}

After doing the training model is successfully carried out, a model with the .hdf5 and .tflite file formats will be generated. In this study, after the training is complete, a plot of model accuracy, plot of model loss, confusion matrix, and classification report will be generated. It can be seen in Figure 8.

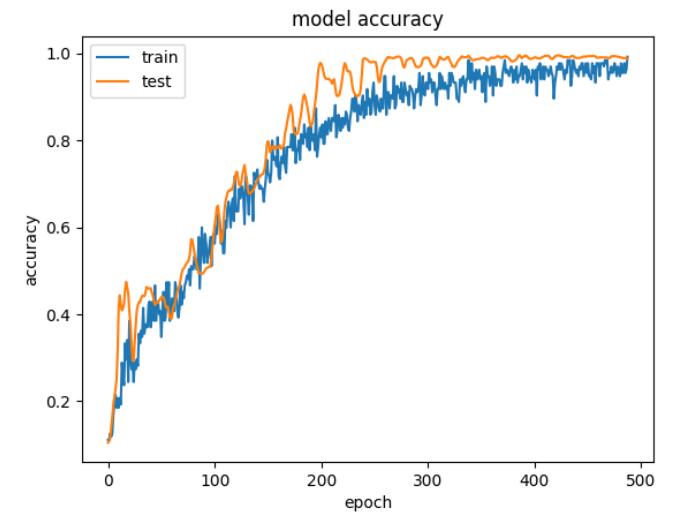

Figure 8. Plot of model accuracy on train and validation datasets

Based on Figure 8, as the epoch increases, the accuracy value should increase. Training accuracy is the value of calculating the accuracy of the training dataset and predictions from the model. While testing accuracy is the result value of calculating the accuracy of testing the dataset and predictions from the model. Usually, the value of testing accuracy will be lower than training accuracy because the model will be optimized for the latter. The final accuracy results from the model training process for the Signal for Help dataset are in Table 4.

TABLE 4

Performance analysis using Deep Neural Network

\begin{tabular}{|l|l|}
\hline Datasets & Signal for Help \\
\hline Classes & 9 \\
\hline Train Accuracy & $99.26 \%$ \\
\hline Test Accuracy & $98.79 \%$ \\
\hline Precision & $98.79 \%$ \\
\hline Recall & $98.79 \%$ \\
\hline F1-score & $98.79 \%$ \\
\hline
\end{tabular}

The plot of model loss on train and validation datasets that generated from the training process can be seen in Figure 9.

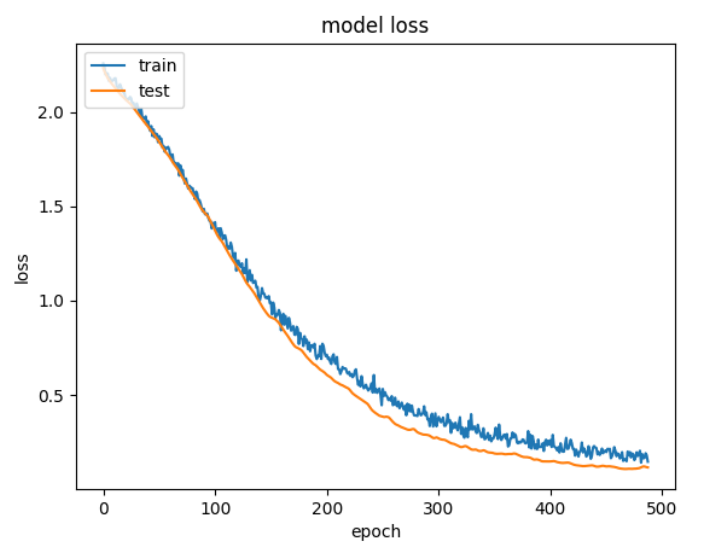

Figure 9. Plot of model loss on train and validation datasets

In Figure 9, as the epoch increases, the loss value should decrease because it is minimized by the neural network. Based on the plot of the loss model above, it can be seen that the training loss and testing loss continue to decrease as the epoch increases. The value of training loss is usually higher than testing loss because the dropout function only applies to the training process and does not apply to the testing. The system will also generate a confusion matrix along with a classification report which is used to visualize the performance of the model. The following Figure 10 and 11 are the confusion matrix and classification report.

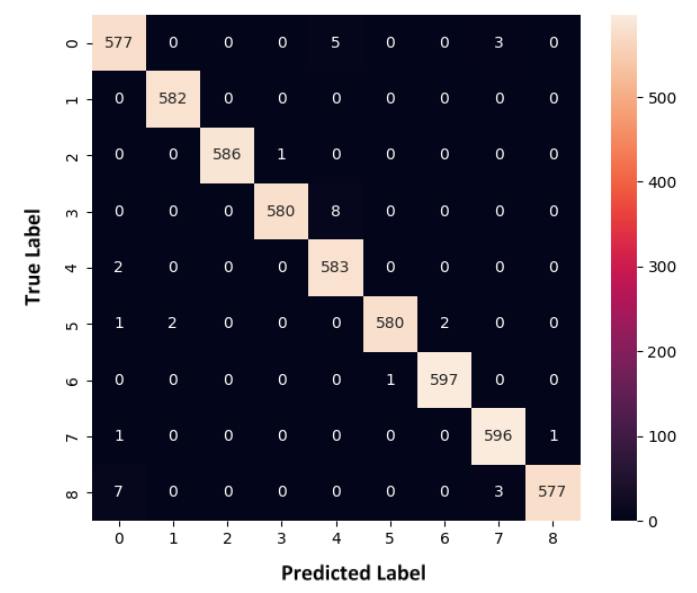

Figure 10. Confusion matrix signal for help dataset 


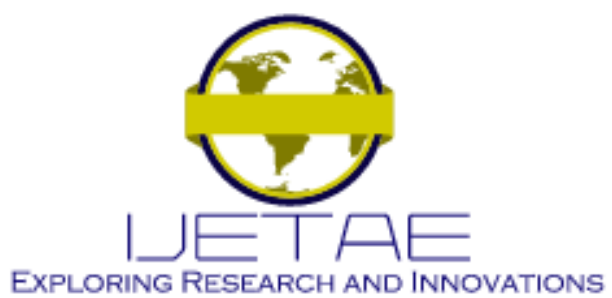

International Journal of Emerging Technology and Advanced Engineering

Website: www.ijetae.com (E-ISSN 2250-2459, Scopus Indexed, ISO 9001:2008 Certified Journal, Volume 12, Issue 02, February 2022)

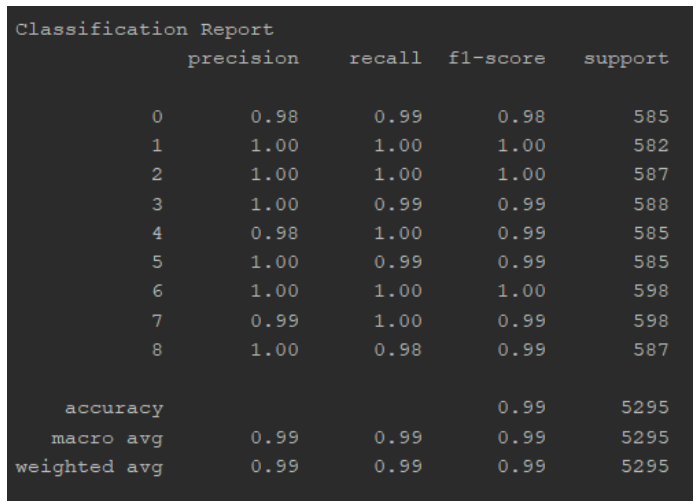

Figure 11. Classification report hand gesture training

After the entire training process is successfully carried out, the system will interpret the model into a .tflite file which will later be used to classify the gestures captured by the camera in real-time. The following Figure 12-15 are the results of the design and development of a hand gesture recognition system as a signal for help.

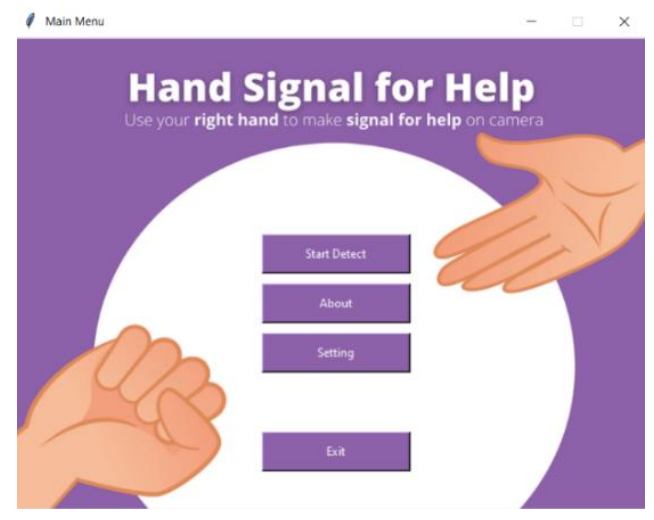

Figure 12. Main menu page screen display

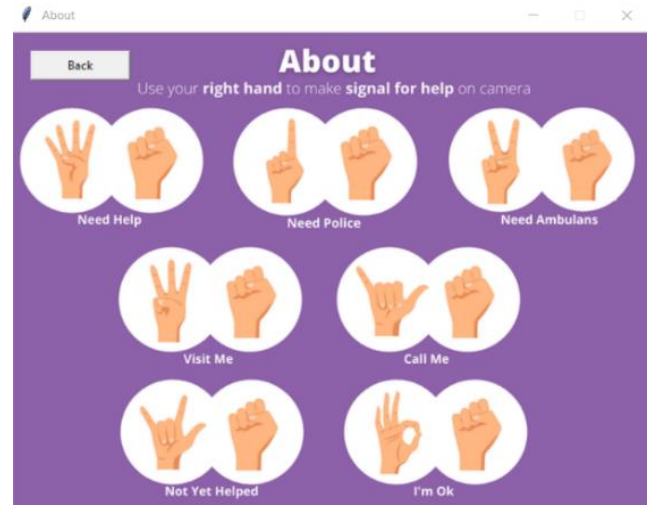

Figure 13. About page screen display

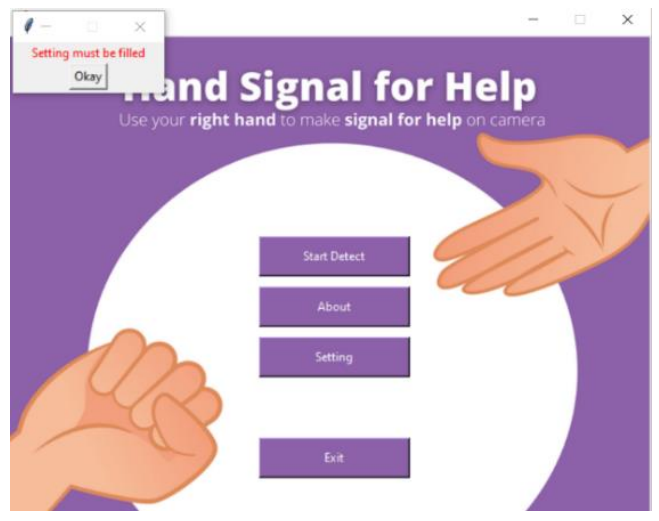

Figure 14. Screen display when settings have not been filled

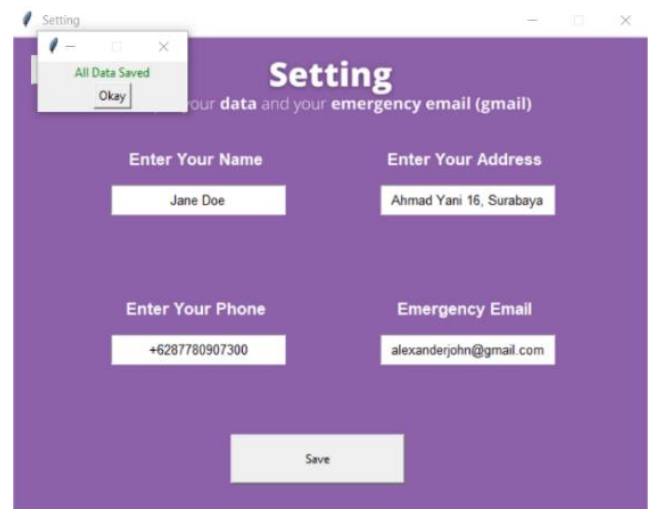

Figure 15. Setting page screen display

To run the system or start detect, user must first fill in the data on the settings page. If the data on the settings page is empty, the user cannot select start detect and there is a message that the user must first fill in the data on the settings page. When all the fields on the settings page have been filled in, when the user selects the Start Detect button, it will go to the hand gesture recognition screen and open the camera to capture real-time images. The following Figure 16 is the result of hand gesture recognition from each gesture. 


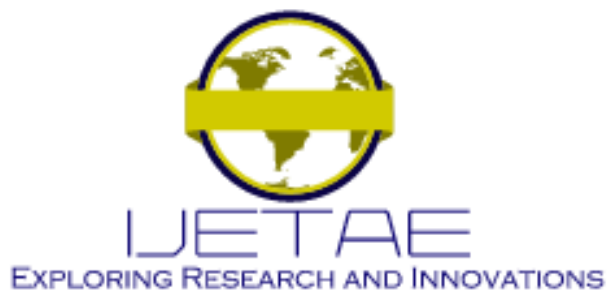

International Journal of Emerging Technology and Advanced Engineering

Website: www.ijetae.com (E-ISSN 2250-2459, Scopus Indexed, ISO 9001:2008 Certified Journal, Volume 12, Issue 02, February 2022)

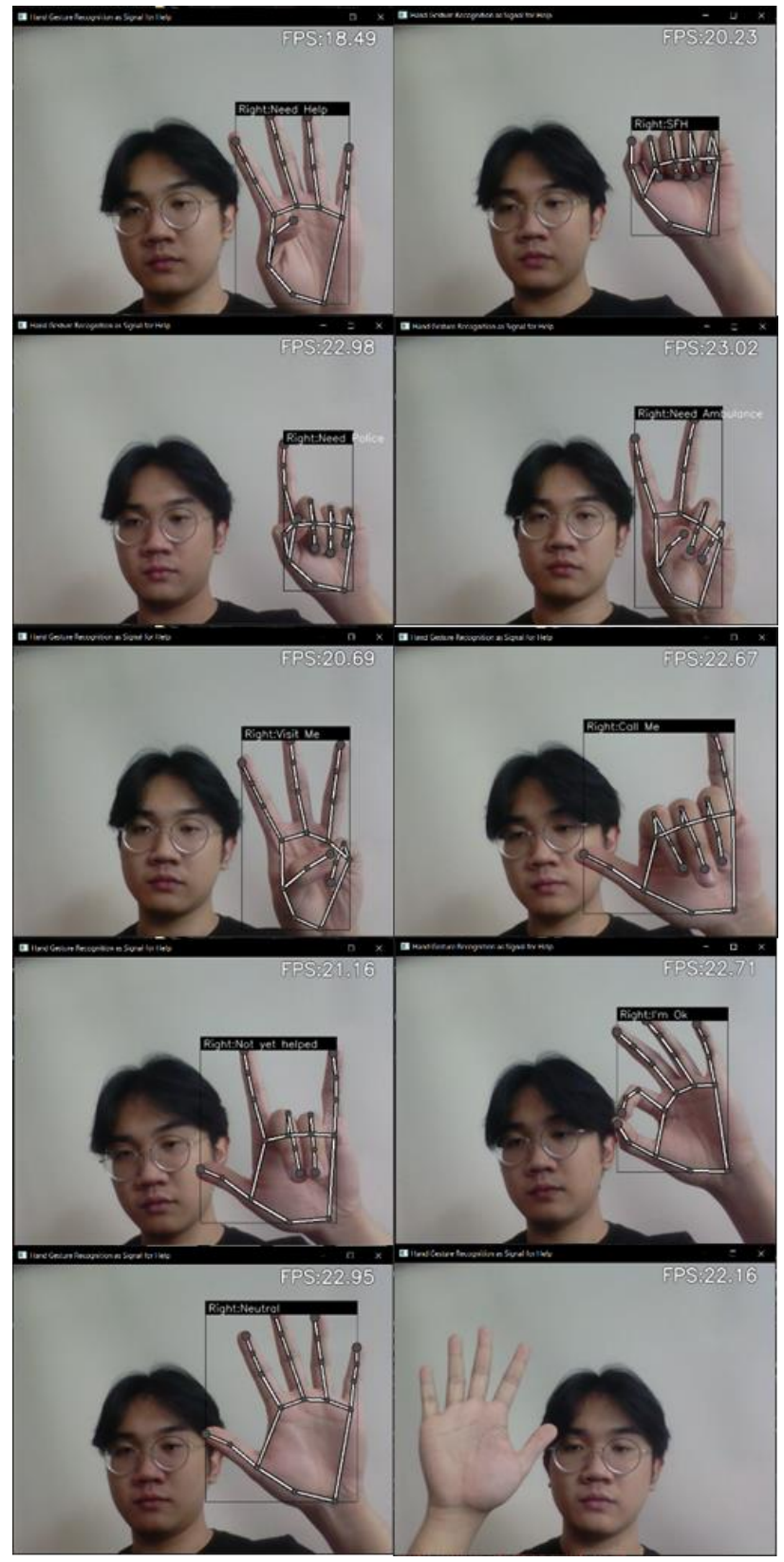

Figure 16. Hand gesture recognition system screen display

To send a request for help via email the user must perform a combination gesture terminated by an SFH gesture. The message sent will match the first gesture created before the SFH gesture. Figure 17 is an example of one of the gestures for sending a request for help message.

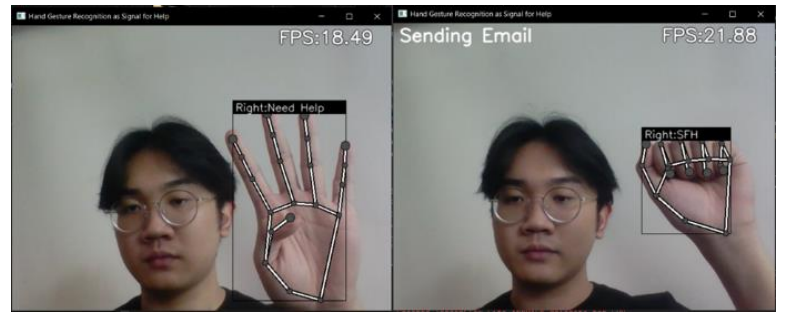

Figure 17. An example of a gesture to send a message requesting help

The following Figure 18 is an example of an email sent and received by an emergency email recipient from each combination of movements made by the user.

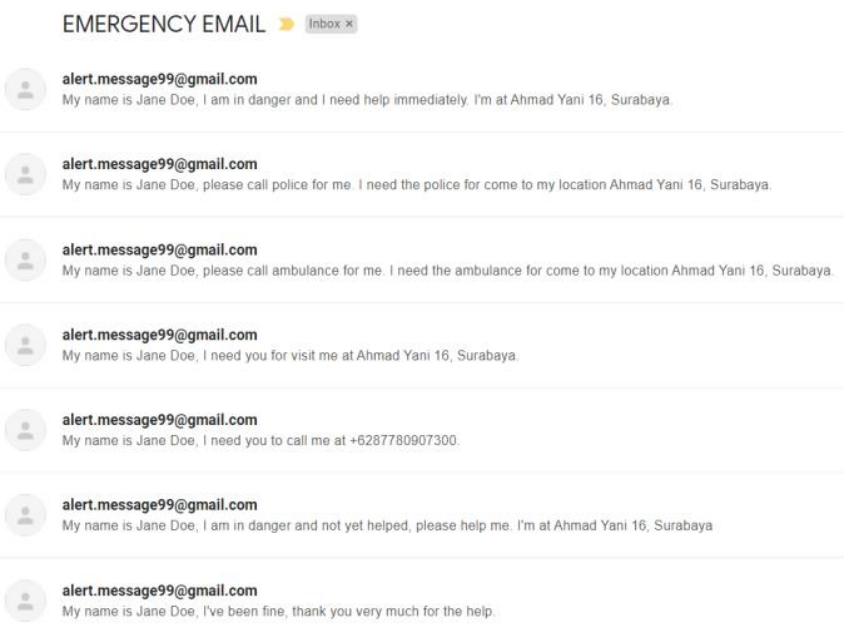

Figure 18. Examples of sending emails of each hand gesture

From the results that have been discussed previously, it can be said that the system built has a good accuracy of $98.79 \%$ and the results of the gesture recognition test are accurate. The performance of the resulting model depends on the training process carried out, the more key points from each hand gesture that are used as input in conducting training, the better the recognition will be. Key point input needs to be taken from each angle or hand position that you want to recognize as the same gesture class to reduce detection failure due to different hand positions or tilts. However, several external factors can affect the performance of hand gesture recognition. The success and failure of the hand gesture recognition process are influenced by the following factors:

- Camera and digital image resolution

- Similarities between defined hand gestures

- The condition of the environment or background at the time of capturing the image in real-time 


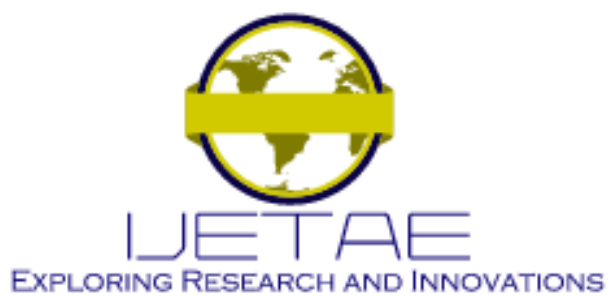

International Journal of Emerging Technology and Advanced Engineering Website: www.ijetae.com (E-ISSN 2250-2459, Scopus Indexed, ISO 9001:2008 Certified Journal, Volume 12, Issue 02, February 2022)

- Angle or movement in the training model

- Position and tilt of the hand

The primary users in this system are people who are in danger and want to ask for help from others. Through this system, the person can send a request for help quickly, easily, and safely with just a hand gesture without speaking. Implementation of this system can be used for personal or public purposes. For personal use, the system can be implemented in the form of Closed-circuit television (CCTV) or smart camera that can be purchased and used individually for personal security, it can be used to send messages requesting help when in danger to emergency contacts. The user can set the email of relatives, friends, or closest people who can be contacted when one day is in a dangerous situation. Its implementation can be accompanied by web or mobile apps connected to a smart camera to manage and change user data or emergency email if changes are needed. The identity of the user or camera owner such as name, the personal address where the camera is placed, and telephone number can be set and linked to the camera system so that the user's identity can be included when the system sends a message requesting help. Instructions and education on how to use the system can also be informed to the user via that web or mobile apps or through the instruction paper packaged with the smart camera.

For public purposes, the system can be implemented to public or traffic cameras on roads and public places for mutual security. So that it can be used for the community when something unwanted happens in a public place, such as traffic accidents, crimes, violence, and so on. For public purposes, emergency contacts can be arranged using the email of the police officer or the nearest community service from the camera installation site. When something threatens safety and security in a public place, the victim or one of the people at the scene can make a hand signal to send a message requesting help to the police or community services. User data can be filled in by the local community service and for user data such as name and address, it can be filled in with the name of the area and address of the public place where the camera is installed. So that the message receiver can find out the location of a public place that needs help when there is danger or things that are not desirable. Instruction or education on how to use can be done through posters posted on roads or in public places where cameras are installed.

\section{CONCLUSION}

1. The development of a hand gesture recognition system as signal for help in this study uses a Deep Neural Network and has an accuracy of $98.79 \%$.

2. Based on the test results, the system has good accuracy in recognizing the specified hand gestures and works properly and correctly to carry out its functions.

3. The design and development of a hand gesture recognition system as a signal for help achieves all of the objectives of this research, namely simplifying the process of asking for help, increasing human security and safety, speeding up the process for requests for help, producing a safe and fast way to ask for help only with hand movements without speak, and reduce the risk of unwanted things happening that can threaten human security and safety.

4. The hand gesture recognition system as signal for help achieves all the benefits of this research, namely providing convenience in the process of asking for help, increasing the need for security and human safety, speed in the process of providing information on requests for help, increasing security and speed in the process of providing information on request for help and reducing the risk of unwanted things that can threaten human security and safety.

5. The performance of the resulting model depends on the training process carried out, the more variations of key points from each hand gesture that are used as input in conducting training, the better the recognition will be.

6. Errors and failures in recognizing can occur due to camera and digital image resolution factors, environmental conditions or background when capturing real-time images, similarities between specified hand gestures, angles or movements in the training model, hand position and tilt.

\section{LIMITATIONS AND FUTURE SCOPE}

This research is the design and development of a hand gesture recognition system as a signal for help. So that in the future, this system can be used for private and public purposes and can be applied to various applications or tools such as CCTV, smart cameras, and so on. The system will detect hand movements in real-time and requests for help will be sent via emergency email with the contents according to the combination of hand signals made by the user. 


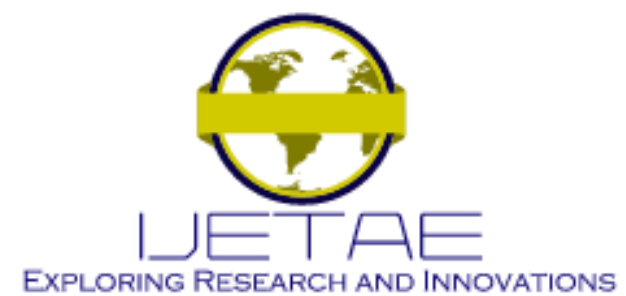

International Journal of Emerging Technology and Advanced Engineering Website: www.ijetae.com (E-ISSN 2250-2459, Scopus Indexed, ISO 9001:2008 Certified Journal, Volume 12, Issue 02, February 2022)

The hand used as input is the right hand and this study did not discuss factors outside the normal, such as hand or finger defects. The sender's email address will be provided by the system so that the user only needs to fill in the data and an emergency email that can be contacted when a moment is in danger.

Based on the limitations of this study, for further research, it is possible to implement the system into various applications such as CCTV smart cameras. The user interface of the system can be improved and more complex features can be added to the system for example using Google APIs for automatic location detection or adding more hand gestures recognized by the system. For data training, other machine learning or deep learning algorithms can be used, and the method of sending messages for requests for help can be changed via WhatsApp or SMS.

\section{REFERENCES}

[1] Halder, A., \& Tayade, A. (2021). Real-time vernacular sign language recognition using mediapipe and machine learning. Journal homepage: www. ijrpr. com ISSN, 2582, 7421.

[2] Wu, W., Shi, M., Wu, T., Zhao, D., Zhang, S., \& Li, J. (2019). Realtime Hand Gesture Recognition Based on Deep Learning in Complex Environments. In 2019 Chinese Control And Decision Conference (CCDC) (pp. 5950-5955). IEEE.

[3] Mujahid, A., Awan, M. J., Yasin, A., Mohammed, M. A., Damaševičius, R., Maskeliūnas, R., \& Abdulkareem, K. H. (2021). Real-Time Hand Gesture Recognition Based on Deep Learning YOLOv3 Model. Applied Sciences, 11(9), 4164.

[4] Nair, R., Singh, D. K., Yadav, S., \& Bakshi, S. (2020). Hand Gesture Recognition system for physically challenged people using IoT. In 2020 6th International Conference on Advanced Computing and Communication Systems (ICACCS) (pp. 671-675). IEEE.

[5] Eshitha, K. V., \& Jose, S. (2018). Hand Gesture Recognition Using Artificial Neural Network. In 2018 International Conference on Circuits and Systems in Digital Enterprise Technology (ICCSDET) (pp. 1-5). IEEE.

[6] Hussain, S., Saxena, R., Han, X., Khan, J. A., \& Shin, H. (2017). Hand gesture recognition using deep learning. In 2017 International SoC Design Conference (ISOCC) (pp. 48-49). IEEE.

[7] Al-Hammadi, M., Muhammad, G., Abdul, W., Alsulaiman, M., Bencherif, M. A., \& Mekhtiche, M. A. (2020). Hand gesture recognition for sign language using 3DCNN. IEEE Access, 8, 79491-79509.

[8] Al-Hammadi, M., Muhammad, G., Abdul, W., Alsulaiman, M., Bencherif, M. A., Alrayes, T. S., ... \& Mekhtiche, M. A. (2020). Deep learning-based approach for sign language gesture recognition with efficient hand gesture representation. IEEE Access, 8, 192527192542.
[9] Abed, A. A., \& Rahman, S. A. (2017). Python-based Raspberry Pi for hand gesture recognition. International Journal of Computer Applications, 975, 8887.

[10] Mohanarathinam, A., Dharani, K. G., Sangeetha, R., Aravindh, G., \& Sasikala, P. (2020). Study on Hand Gesture Recoginition by using Machine Learning. In 2020 4th International Conference on Electronics, Communication and Aerospace Technology (ICECA) (pp. 1498-1501). IEEE.

[11] Samgiskar, S., Sakharkar, D., Sonawane, P., Jadhav, R., \& Shahare, Y. (2019) . Hand Gesture Recognition for Sign Language using CNN. International Journal for Scientific Research \& Development, Vol. 7, Issue 03, 2019.

[12] Jaramillo, A. G., \& Benalcázar, M. E. (2017). Real-time hand gesture recognition with EMG using machine learning. In 2017 IEEE Second Ecuador Technical Chapters Meeting (ETCM) (pp. 15). IEEE.

[13] Naik, N., \& Mehta, M. A. (2018). Hand-over-Face Gesture based Facial Emotion Recognition using Deep Learning. In 2018 International Conference on Circuits and Systems in Digital Enterprise Technology (ICCSDET) (pp. 1-7). IEEE.

[14] Sun, J. H., Ji, T. T., Zhang, S. B., Yang, J. K., \& Ji, G. R. (2018, December). Research on the hand gesture recognition based on deep learning. In 2018 12th International Symposium on Antennas, Propagation and EM Theory (ISAPE) (pp. 1-4). IEEE.

[15] Kaur, S., \& Nair, N. (2018). Electronic Device Control Using Hand Gesture Recognition System For Differently Abled. In 2018 8th International Conference on Cloud Computing, Data Science \& Engineering (Confluence) (pp. 371-375). IEEE.

[16] Ehrnsperger, M. G., Brenner, T., Hoese, H. L., Siart, U., \& Eibert, T. F. (2020). Real-Time Gesture Detection Based on Machine Learning Classification of Continuous Wave Radar Signals. IEEE Sensors Journal, 21(6), 8310-8322.

[17] Ismail, A. P., Abd Aziz, F. A., Kasim, N. M., \& Daud, K. (2021). Hand gesture recognition on python and opencv. In IOP Conference Series: Materials Science and Engineering (Vol. 1045, No. 1, p. 012043). IOP Publishing.

[18] Niiuchi, R., Kang, H., \& Iwamura, K. (2018). Detection of Human Motion Gestures Using Machine Learning for Actual Emergency Situations. In 2018 IEEE 7th Global Conference on Consumer Electronics (GCCE) (pp. 492-496). IEEE.

[19] Goralski, M. A., \& Tan, T. K. (2020). Artificial intelligence and sustainable development. The International Journal of Management Education, 18(1), 100330

[20] Patel, Krishna \& Raina, Sachin \& Gupta, Saurabh. (2020). Artificial Intelligence and its Models. Journal of Applied Science and Computations, 8(2), 1076-5131 (pp. 95-97). 